\title{
Inhibition of Mitochondrial Functions by Margosa Oil: Possible Implications in the Pathogenesis of Reye's Syndrome ${ }^{1}$
}

\author{
Y. KOGA, I. YOSHIDA, A. KIMURA, M. YOSHINO, F. YAMASHITA, AND D. SINNIAH \\ Department of Pediatrics and Child Health, Kurume University School of Medicine, Kurume, Japan \\ [Y.K., I.Y., A.K., M.Y., F.Y.] and Department of Pediatrics, Faculty of Medicine, University of Malaya,
} Kuala Lumpur, Malaysia [D.S.]

\begin{abstract}
Margosa oil (MO), a fatty acid-rich extract of the seeds of the neem tree and a reported cause of Reye's syndrome, has been used in the induction of an experimental model of Reye's syndrome in rats. It has been reported that MO causes a decrease in in vivo mitochondrial enzyme activity similar to that seen in Reye's syndrome. We have attempted to uncover some of the biochemical mechanisms of MO's toxicity by examining its effect in vitro on isolated rat liver mitochondria. Male rat liver mitochondria were isolated by centrifugation; oxygen uptake, reduced forms of cytochrome $b, c+c_{1}, a+a_{3}$, and flavoprotein, intramitochondrial concentrations of acetyl coA, acid-soluble coA, acid-insoluble coA, and ATP content were measured after incubation with and without MO. Our results reveal that MO is a mitochondrial uncoupler. State 4 respiration was increased while the respiratory control ratio was decreased. The intramitochondrial content of ATP was also decreased. There were substantial changes in the reduction of the respiratory chain components after incubation of mitochondria with MO. This decelerative effect on mitochondrial electron transport was alleviated by the addition of coenzyme $Q$ and/or carnitine. These effects of MO on mitochondrial respiration may be due to changes in fatty acid metabolism caused by MO as MO caused a shift in the proportion of acid-soluble or acid-insoluble coA esters. Supplementary therapy with $L$-carnitine and coenzyme $Q$ may be useful in the management of MO-induced Reye's syndrome. (Pediatr Res 22: 184-187, 1987)
\end{abstract}

\section{Abbreviations}

MO, margosa oil

RS, Reye's syndrome

CoQ, coenzyme $Q$

RCR, respiratory control ratio

MO, an extract of the seeds of the neem tree (Azadirachta indica A. Juss) distributed throughout the Indo-Malayan region, is used as a traditional remedy by the Hindu. This oil is known to cause RS in infants (1) and can induce symptoms similar to those of RS in rats (2). Several lines of morphological and

Received March 4, 1986; accepted March 3, 1987.

Reprint requests and correspondence Dr. Yasutoshi Koga, Department of Pediatrics and Child Health, Kurume University School of Medicine, 67, Asahimachi, Kurume, Japan 830.

Supported by Grants for Reye's syndrome research from the Ministry of Health and Welfare, Japan.

${ }^{1}$ Presented in part at the first Asian Symposium on Reye's Syndrome and Mitochondrial Diseases, Kurume, October 6, 1985. biochemical evidence imply that in $\mathrm{RS}$ the mitochondrion is the major site of insult (3). Plasma from RS patients induce respiratory inhibition of isolated rat liver mitochondria (4). Similar effects have been reported with salicylates and salicyl compounds which are known to be associated with RS (5). Although there are several reports relating to the production of Reye-like hepatic mitochondrial enzyme deficits in the rat by MO there is no report on the in vitro effects of $\mathrm{MO}$ on the functions of isolated liver mitochondria $(6,7)$. Therefore, we designed this study to evaluate the effects of MO on isolated rat liver mitochondrial functions, and to determine if the effects of MO could be reversed by $\mathrm{D}, \mathrm{L}$-carnitine or coenzyme $\mathrm{Q}$.

In view of the fact that major constituents of $\mathrm{MO}$ are longand medium-chain fatty acids (8), it appears likely that these fatty acids may be involved in the mechanism of the toxicity of MO. Recently, secondary carnitine deficiency has been reported in several inherited metabolic diseases (9) and RS (10). Since Lcarnitine serves not only as a vehicle of fatty acid transport into mitochondria but enhances regeneration of free $\mathrm{CoA}-\mathrm{SH}$ in mitochondria (11), it may relieve the toxicity of MO on mitochondria if MO disrupts mitochondrial functions in a manner similar to that of fatty acids. On the other hand, MO also contains other mitochondrial toxins such as terpenoids (nimbin, nimbiol), which have a similar structure to $\mathrm{CoQ}$, and have been used as insecticides. These compounds may act as electron acceptors which are competitive to CoQ. CoQ not only serves as a component of the mitochondrial respiratory chain, but it protects mitochondrial membranes against the injury induced by accumulated long-chain acyl CoA and long-chain acyl carnitine and lowers the production of intramitochondrial superoxide (12). Therefore, we tested whether or not the supplementation with coenzyme $\mathrm{Q}$ is effective in preventing the toxicity of $\mathrm{MO}$ on mitochondria in vitro.

\section{MATERIALS AND METHODS}

Mitochondria were isolated from the liver of rats using the method of Hogeboom et al. (13) with sight modification (13). Male Wistar rats (180-270 g) starved for $24 \mathrm{~h}$ were anesthetized with diethylether and killed by decapitation.

The livers were removed, weighed, and rapidly homogenized in 10 volumes of ice-cold medium containing $70 \mathrm{mM}$ sucrose, $210 \mathrm{mM}$ mannitol, $0.1 \mathrm{mM}$ EDTA, $10 \mathrm{mM}$ Tris- $\mathrm{HCl}, \mathrm{pH} 7.4$, in Potter-Elvehjem type glass-Teflon homogenizer (Pyrex Iwaki Glass Co., Tokyo, Japan). The homogenate was centrifuged for $10 \mathrm{~min}$ at $700 \times \mathrm{g}$, and the supernatant was centrifuged for 10 min at $8000 \times g$. The sediment was suspended in the same medium and centrifuged for $5 \mathrm{~min}$ at $700 \times g$ to remove remaining cell debris and the supernatant was recentrifuged for $10 \mathrm{~min}$ at $9000 \times g$. The mitochondrial sediment was resus- 
pended in the incubation medium containing $250 \mathrm{mM}$ mannitol, $10 \mathrm{mM}$ potassium phosphate, $2 \mathrm{mM} \mathrm{MgCl}, 0.2 \mathrm{mM}$ EDTA, 10 $\mathrm{mM} \mathrm{KCl}, 10 \mathrm{mM}$ Tris- $\mathrm{HCl}, \mathrm{pH} 7.4$, in a volume numerically equal (in $\mathrm{ml}$ ) to the original weight (in $\mathrm{g}$ ) of the liver. Thus 1.0 $\mathrm{ml}$ of this suspension was derived from $1.0 \mathrm{~g}$ of liver.

The protein contents of the primary mitochondrial suspensions varied from 7.2 to $11.8 \mathrm{mg} / \mathrm{ml}$. The morphological purity of the preparations was checked by electron microscopy.

Oxygen uptake by the mitochondria was measured polarographically with a Clark-type oxygen electrode (Yanaco model PO 100-A, Yanagimoto Co., Tokyo, Japan), according to the method of Chance and Williams (14). Incubation was carried out at $30^{\circ} \mathrm{C}$ in the incubation medium with a $\mathrm{pH}$ of 7.4 , containing $250 \mathrm{mM}$ mannitol, $10 \mathrm{mM}$ potassium phosphate, 2 $\mathrm{mM} \mathrm{MgCl} 2,0.2 \mathrm{mM}$ EDTA, $10 \mathrm{mM} \mathrm{KCl}, 10 \mathrm{mM}$ Tris- $\mathrm{HCl}$, and $19.8 \mu \mathrm{g}$ rotenone, with and without additions of $\mathrm{MO}$ at concentrations of 2.5 or $25 \mu \mathrm{l} / \mathrm{ml}$ of the incubation medium, respectively. Then $3.3 \mu \mathrm{mol}$ succinate was added, followed by 1.98 $\mu \mathrm{mol} \mathrm{ADP}$ in a total volume of $3.3 \mathrm{ml}$. ATP content in the incubation medium was measured enzymatically according to the method of Bücher (15), using an ATP-kit (Boehringer-Mannheim Co., Mannheim, West Germany). Protein content was measured by the method of Lowry et al. (16). Quantitative analysis of cytochromes $\mathrm{b}, \mathrm{c}+\mathrm{c}_{1}$, and $\mathrm{a}+\mathrm{a}_{3}$, and flavoprotein was carried out according to the method of Chance and Hagihara (17) by measuring differences in spectra between the anaerobic and aerobic states at room temperature using a Shimadzu UV3000 split-beam spectrophotometer (Shimadzu, Kyoto, Japan).

The incubation conditions were similar to that used for the study of mitochondrial respiration, except that the final incubation volume was $1.5 \mathrm{ml}$, rotenone was not added, and the final protein concentration was $2.9 \mathrm{mg}$ per incubation. The mitochondrial suspensions in both sample and reference cuvettes were first made aerobic by shaking with air and then, one of the following substrates was added to the sample cuvette: $1.5 \mu \mathrm{mol}$ succinate, $1.5 \mu \mathrm{mol}$ pyruvate, or $3.0 \mu \mathrm{mol} \mathrm{D}, \mathrm{L}$-isocitrate, to give final concentrations of $1.0,1.0$, and $2.0 \mathrm{mM}$, respectively. The reference cuvette receives the same volume of the incubation medium. The mitochondria were allowed to become anaerobic by the endogenous respiration after the addition of substrate. In some experiments, D, L-carnitine and/or coenzyme $\mathrm{Q}$ were added at final concentrations of 50 and $0.1 \mathrm{mM}$, respectively. The measurements of ATP concentration were carried out using the same aliquots which were incubated for $30 \mathrm{~min}$ at $30^{\circ} \mathrm{C}$. Concentration of acetyl-CoA, acid-soluble $\mathrm{CoA}$, and acid-insoluble CoA were measured by the enzymatic method (18) with the other aliquots after they were fractionated according to the procedure of Ingebresten et al. (19).

\section{RESULTS}

When succinate was used as a substrate for mitochondrial respiration, mean values of $\mathrm{RCR} A D P / O$ ratio, the $A T P$ content in control incubations were $5.05 \pm 0.22,1.90 \pm 0.05$, and 1.31 $\pm 0.21 \mu \mathrm{mol} / \mathrm{mg}$ of mitochondrial protein, respectively (Table 1). $\mathrm{MO}$ at a concentration of $2.5 \mu \mathrm{l} / \mathrm{ml}$ stimulated state 4 respiration, inhibited state 3 respiration, and caused a decrease in RCR to $34.9 \%$ of the control values. At a concentration of 25 $\mu \mathrm{l} / \mathrm{ml} \mathrm{MO}$ caused a profound uncoupling of oxidative phosphorylation and decreased the ATP content to $45.0 \%$ of the control mean value.

The concentrations of reduced forms of flavoprotein and cytochromes in control incubations are presented in Table 2. By 5 min after the addition of succinate, all reduced forms of the cytochromes were recognizable. The concentrations of all the reduced components were calculated at 5 and $10 \mathrm{~min}$ after the addition of succinate to evaluate the effects of MO. The levels of the reduced cytochromes were significantly decreased 5 and 10 min after the addition of $\mathrm{MO}$ at the concentration of $2.5 \mu \mathrm{l} / \mathrm{ml}$. The decreases in the levels of the reduced cytochromes which were caused by MO were partially alleviated by the additions of $\mathrm{D}, \mathrm{L}$-carnitine, and they recovered to the levels similar to those of control values by the additions of CoQ or both. The content of ATP in the incubation solutions was significantly decreases by the addition of $\mathrm{MO}$ at $2.5 \mu \mathrm{l} / \mathrm{ml}$ per incubation (Table 2). The ATP levels recovered to $82.1 \%$ of control values following the addition of $\mathrm{CoQ}$.

Incubation of isolated rat liver mitochondria with $2.5 \mu \mathrm{l} / \mathrm{ml}$ MO resulted in decreased intramitochondrial levels of acetyl $\mathrm{CoA}$ and acid-soluble $\mathrm{CoA}$, and increased levels of acid-insoluble $\mathrm{CoA}$ (Table 3). These effects of MO seemed to be dose dependent.

\section{DISCUSSION}

The clinicopathological findings in RS implicate the mitochondrion as the primary site of involvement $(3,20)$. It is, therefore, possible for mitochondrial toxins to induce RS. It has recently been reported that MO can trigger RS in infants (1) and that it can mimic symptoms similar to those in RS in animal model in vivo (2). Therefore, we designed this study to investigate the effects of MO on some mitochondrial functions. The major components of $\mathrm{MO}$ are long-chain, saturated and unsaturated fatty acids (mainly stearic, oleic, palmitic, linoleic, and smaller amounts of myristic, arachidic, and behenic) (8), and mediumchain fatty acids in smaller quantities. It also contains small amounts of nimbin and nimbiol. These compounds have a terpenoid skeleton which is shared by CoQ. They have been used as insecticides such as rotenone. These compounds act as electron acceptors which are competitive to CoQ. Since long- and medium-chain fatty acids have detergent effect, it is possible that MO exerts a destructive effect on mitochondrial membranes. Moreover, the depletion of the intramitochondrial levels of acetyl $\mathrm{CoA}$ and acid-soluble CoA may inhibit several mitochondrial enzyme activities (3). Trauner (21) reported that a continuous infusion of octanoate can induce pathologic abnormalities in the rabbit similar to those observed in patients with RS. Octanoate is a potent uncoupler of oxidative phosphorylation $(22,23)$. Ogburn et al. (24) found increases in serum levels of long-chain

Table 1. Effects of $M O$ on state 3 and state 4 rates of $\mathrm{O}_{2}$ consumption, $\mathrm{RCR}$, ADP/O ratio, and intramitochondrial ATP content*

\begin{tabular}{lccccc}
\hline \multicolumn{1}{c}{ Incubations } & State 3 & State 4 & RCR & ADP/O & ATP \\
\hline Control $(10)$ & $188.4 \pm 36.5$ & $37.3 \pm 7.15$ & $5.05 \pm 0.22$ & $1.90 \pm 0.05$ & $1.31 \pm 0.21$ \\
Margosa $+2.5 \mu \mathrm{l} / \mathrm{ml}(7)$ & $138.1 \pm 12.0 \dagger$ & $77.5 \pm 6.71 \dagger$ & $1.76 \pm 0.12 \dagger$ & $1.81 \pm 0.04 \dagger$ & $1.15 \pm 0.22$ \\
$+25 \mu \mathrm{l} / \mathrm{ml}(7)$ & $\ddagger$ & $\ddagger$ & $\ddagger$ & $\ddagger$ & $0.59 \pm 0.15 \dagger$ \\
\hline
\end{tabular}

* The values of oxygen consumption represent mean \pm SD natom oxygen per min per mg protein. The values of ATP concentration represent mean $\pm \mathrm{SD} \mu \mathrm{mol}$ per $10 \mathrm{~min}$ per mg protein. The numbers in parentheses represent numbers of experiments.

$\dagger$ Values were significantly less $(p<0.01)$ with a one-tailed $t$ tested for independent mean probability.

$¥ \mathrm{MO}$ at a concentration of $25 \mu \mathrm{l} / \mathrm{ml}$ showed linear line from the point of state 2 in oxogroph. We cannot recognize the distinction between state 4 and state 3 oxygen consumption. The state 4 oxygen consumption rate was closer to the state 3 rate. This indicates as a profound uncoupling effect. When substrate is present, ADP induces an increased rate of oxygen consumption (state 3 ). The slower state 4 rate is resumed when all the ADP is phosphorylated. ADP/O ratio are calculated by dividing the known amount of added ADP by the measured oxygen consumption during state 3 . 
Table 2. Effects of MO on mitochondrial respiratory chain components and intramitochondrial ATP content*

\begin{tabular}{|c|c|c|c|c|c|c|c|c|c|}
\hline \multirow[b]{2}{*}{ Additions } & \multicolumn{4}{|c|}{$5 \mathrm{~min}$} & \multicolumn{4}{|c|}{$10 \mathrm{~min}$} & \multirow{2}{*}{$\frac{30 \mathrm{~min}}{\mathrm{ATP}}$} \\
\hline & Fp & Cyt b & Cyt $c+c_{1}$ & Cyt $a+a_{3}$ & $\mathrm{Fp}$ & Cyt b & Cyt $c+c_{1}$ & Cyt $a+a_{3}$ & \\
\hline \multirow[t]{2}{*}{ Control (10) } & 0.49 & 0.12 & 0.17 & 0.12 & 0.61 & 0.11 & 0.19 & 0.11 & 1.06 \\
\hline & \pm 0.05 & \pm 0.02 & \pm 0.03 & \pm 0.02 & \pm 0.07 & \pm 0.02 & \pm 0.03 & \pm 0.03 & \pm 0.12 \\
\hline \multirow[t]{2}{*}{ +D,L-carnitine $50 \mu \mathrm{M}(7)$} & 0.60 & 0.10 & 0.18 & 0.11 & 0.70 & 0.11 & 0.17 & 0.09 & 0.98 \\
\hline & $\pm 0.21 \dagger$ & \pm 0.02 & \pm 0.03 & \pm 0.01 & \pm 0.23 & \pm 0.02 & \pm 0.03 & \pm 0.02 & \pm 0.08 \\
\hline \multirow{2}{*}{$\begin{array}{l}+ \text { Coenzyme Q } 0.1 \mathrm{mM} \\
\text { (7) }\end{array}$} & 0.59 & 0.10 & 0.16 & 0.12 & 0.69 & 0.10 & 0.18 & 0.10 & 0.90 \\
\hline & \pm 0.10 & \pm 0.02 & \pm 0.02 & \pm 0.03 & \pm 0.10 & \pm 0.01 & \pm 0.03 & \pm 0.02 & \pm 0.21 \\
\hline$+\mathrm{D}, \mathrm{L}$-carnitine $50 \mu \mathrm{M}$ & 0.53 & 0.10 & 0.18 & 0.13 & 0.62 & 0.10 & 0.17 & 0.11 & 0.95 \\
\hline $\begin{array}{l}\text { Coenzyme Q } 0.1 \mathrm{mM} \\
\text { (7) }\end{array}$ & \pm 0.16 & \pm 0.02 & \pm 0.03 & \pm 0.04 & \pm 0.20 & \pm 0.02 & \pm 0.03 & \pm 0.02 & \pm 0.17 \\
\hline \multirow[t]{2}{*}{$\mathrm{MO} 2.5 \mu \mathrm{l} / \mathrm{ml}$} & 0.48 & 0.04 & 0.08 & 0.03 & 0.61 & 0.09 & 0.13 & 0.07 & 0.27 \\
\hline & \pm 0.31 & \pm 0.03 & $\pm 0.04 \ddagger$ & $\pm 0.03 \ddagger$ & \pm 0.20 & \pm 0.03 & $\pm 0.02 \ddagger$ & $\pm 0.01 \neq$ & $\pm 0.05 \ddagger$ \\
\hline \multirow[t]{2}{*}{$+\mathrm{D}, \mathrm{L}$-carnitine $50 \mu \mathrm{M}(7)$} & 0.51 & 0.09 & 0.13 & 0.09 & 0.58 & 0.10 & $0.17^{\circ}$ & 0.09 & 0.35 \\
\hline & \pm 0.18 & $\pm 0.02 \dagger$ & \pm 0.05 & $\pm 0.04 \dagger$ & \pm 0.15 & \pm 0.01 & \pm 0.03 & \pm 0.02 & $\pm 0.06 \ddagger$ \\
\hline \multirow{2}{*}{$\begin{array}{l}+ \text { Coenzyme Q } 0.1 \mathrm{mM} \\
\text { (7) }\end{array}$} & 0.53 & 0.10 & 0.16 & 0.10 & 0.61 & 0.10 & 0.18 & 0.08 & 0.87 \\
\hline & \pm 0.16 & \pm 0.02 & \pm 0.03 & \pm 0.03 & \pm 0.17 & \pm 0.02 & \pm 0.03 & \pm 0.03 & $\pm 0.23 \dagger$ \\
\hline$+\mathrm{D}, \mathrm{L}$-carnitine $50 \mu \mathrm{M}$ & 0.55 & 0.09 & 0.16 & 0.11 & 0.61 & 0.10 & 0.16 & 0.10 & 0.89 \\
\hline $\begin{array}{l}\text { Coenzyme Q } 0.1 \mathrm{mM} \\
\text { (7) }\end{array}$ & \pm 0.15 & $\pm 0.02 \dagger$ & \pm 0.03 & \pm 0.02 & \pm 0.20 & \pm 0.01 & \pm 0.04 & \pm 0.02 & $\pm 0.19 \dagger$ \\
\hline
\end{tabular}

* The values of respiratory chain components represent mean \pm SD nmol $/ \mathrm{mg}$ protein. The values of ATP concentration represent mean \pm SD $\mu \mathrm{mol} / \mathrm{mg}$ protein per $30 \mathrm{~min}$. The numbers in parentheses represent numbers of experiments.

$\dagger$ Values were significantly less $(p<0.05)$ using a one-tailed $t$ tested for independent mean probability.

$\ddagger$ Values were significantly less $(p<0.01)$ using a one-tailed $t$ tested for independent mean probability.

Table 3. Effects of MO on intramitochondrial CoA esters*

\begin{tabular}{lcccc}
\hline \multicolumn{1}{c}{ Incubations } & Acetyl CoA & Acid-soluble & Acid-insoluble & Total CoA \\
\hline Control (6) & $0.52 \pm 0.05$ & $1.06 \pm 0.05$ & $0.88 \pm 0.09$ & $1.93 \pm 0.11$ \\
Margosa $+2.5 \mu \mathrm{l} / \mathrm{ml}(6)$ & $0.38 \pm 0.02 \dagger$ & $0.72 \pm 0.02 \dagger$ & $1.64 \pm 0.04 \ddagger$ & $2.06 \pm 0.05$ \\
$+25 \mu \mathrm{l} / \mathrm{ml}(6)$ & $0.29 \pm 0.02 \ddagger$ & $0.60 \pm 0.04 \dagger$ & $1.80 \pm 0.06 \ddagger$ & $2.15 \pm 0.11$ \\
\hline
\end{tabular}

* The values of coenzyme A components represent mean $\pm \mathrm{SD} \mathrm{nmol} / \mathrm{mg}$ protein. The numbers in parentheses represent numbers of experiments. Acid-soluble CoA includes free CoA-SH, soluble acyl derivatives (acetyl CoA, succinyl CoA etc.), and acid-insoluble CoA includes long chain acyl CoA derivatives $\left(\mathrm{C}_{10}-\mathrm{C}_{12}\right.$ or higher).

$\dagger$ Values were significantly less $(p<0.05)$ using a one-tailed $t$ tested for independent mean probability.

$\ddagger$ Values were significantly less $(p<0.01)$ using a one-tailed $t$ tested for independent mean probability.

polyunsaturated fatty acids, some of which are constituents of $\mathrm{MO}$, in patients with RS.

Our results show that MO uncouples mitochondrial oxidative phosphorylation, inhibits the respiratory chain at a site between $\mathrm{FP}_{2}$ and cytochrome $\mathrm{b}$, decreases intramitochondrial levels of acetyl CoA and acid-soluble CoA esters, and reduces the content of ATP in mitochondria. However, Greene et al. (25) reported no reduction of ATP content in the liver from patients with RS. Kang et al. (26) reported concentrations of the acid-soluble CoA esters were higher in Reye's liver samples than in samples from controls. It has been shown that fatty acids uncouple oxidative phosphorylation $(27,28)$ and that they enhance the activity of ATPase (29). The MO-induced decline in the level of ATP and retardation of reduction in cytochromes in vitro are very likely to be linked with these properties of fatty acids. The presence of fatty acids in excessive amounts would produce a decline in the mitochondrial levels of ATP and CoA-SH through acylation. These mechanisms probably partly account for the MO-induced decline in the ATP level (Table 2) and for the decrease in acetyl $\mathrm{CoA}$ which was associated with a concomitant increase in the acid-insoluble CoA fraction (Table 3 ).

The decreases in the reduced forms of cytochromes induced by the addition of MO were alleviated partly by the inclusion of D,L-carnitine (Table 2). This alleviation is presumably caused by the decrease in fatty acyl-CoAs by the removal of nonesterified fatty acids through acylation with carnitine. Carnitine serves not only as a vehicle of fatty acid transport into mitochondria, but it enhances regeneration of free CoA-SH in mitochondria via formation of acylcarnitines from acyl-CoA derivations $(11,30)$. The availability of carnitine is closely related to nutritional status (31). Therefore, the toxicity of MO may be amplified when it is given to malnourished children. The decreased levels of ATP content were alleviated by the addition of coenzyme $Q$ or coenzyme Q plus carnitine. CoQ has an ATP-conserving effect, protects the membrane structure, and lowers the generation of superoxide (12).

Our results suggest that $\mathrm{MO}$ is a potent mitochondrial toxin. It uncouples mitochondrial oxidative phosphorylation, inhibits the respiratory chain, decreases intramitochondrial acetyl $\mathrm{CoA}$ and free $\mathrm{CoA}-\mathrm{SH}$, and finally causes a mitochondrial energy crisis. These in vitro observations lead us to speculate that MO causes RS in some nutritionally compromised children. Moreover, the alleviation of MO-induced mitochondrial dysfunction by the addition of carnitine and coenzyme $Q$ in vitro raises the possibility that several metabolic abnormalities in MO-induced RS are partly correctable by coenzyme Q and carnitine.

In RS, the occurrence of lactic acidosis, hyperammonemia, hypoglycemia, and fatty liver is well documented (20), as is the case with in the MO-induced Reye-like syndrome (1). In view of the fact that acetyl-CoA serves as substrate, together with oxaloacetate, for citrate synthesis, and that acetyl-CoA is an obligatory positive effector on pyruvate carboxylase (32), the MOinduced decline in acetyl-CoA level is likely to diminish influx of citrate into citric acid cycle. This seems to be partly related to 
lactic acidosis. Gluconeogenesis from lactate and pyruvate would be inhibited due to the depletions of ATP and acetyl CoA which are induced by MO. Since the priming reaction of the $\beta$-oxidation of fatty acids requires ATP and CoA-SH, the decrease in the intramitochondrial free-CoA pool and low ATP conditions may inhibit $\beta$-oxidation of fatty acids. This would partially lead to the fatty liver seen in both RS- and MO-induced RS. Since acetyl-CoA is a substrate for synthesis of $\mathrm{N}$-acetylglutamate, the depletion of acetyl-CoA may inhibit the synthesis of $\mathrm{N}$-acetylglutamate (33). This may result in an insufficient nitrogen disposal leading to hyperammonemia. These mechanisms may partly account for the clinical and biochemical manifestations of RS induced by MO. Supplementative therapy with L-carnitine and CoQ may be effective in dealing with MO-induced RS.

\section{REFERENCES}

1. Sinniah D, Baskaran G 1981 Margosa oil poisoning as a cause of Reye's syndrome. Lancet 1:487-489

2. Sinniah D, Schwartz PH, Mitchell RA, Arcinue EL 1985 Investigation of an animal model of a Reye-like syndrome caused by margosa oil. Pediatr Res 19:1346-1355

3. Mitchell RA, Arcinue EL, Partin JC, Ram ML, Chang CH, Smialek J, Sarnaik A 1985 Quantitative evaluation of the extent of hepatic enzyme changes in Reye syndrome compared with normal liver or with non-Reye liver disorders: objective criteria for animal models. Pediatr Res 19:19-22

4. Segalman TY, Lee CP 1982 Reye's syndrome: plasma-induced alterations in mitochondrial structure and function. Arch Biochem Biophys 214:522-530

5. Martens ME, Lee CP 1984 Reye's syndrome: salicylates and mitochondrial functions. Biochem Pharmacol 33:2869-2876

6. Sinniah D, Arcinue EL, Mitchell RA, Schwarz PH 1983 A possible animal model of Reye's syndrome using margosa oil. Pediatr Res 17:295A(abstr)

7. Mitchell RA, Arcinue EL, Sinniah D, Ram ML, Schwarz PH 1985 Production of Reye-like mitochondrial hepatic enzyme deficits in the rat by Margosa oil. Fed Proc 44:1804(abstr)

8. Skellon JH, Thorburn S, Spence J, Chatterjee SN 1962 The fatty acids of neem oil and their reduction products. J Sci Food Agric 13:639-643

9. Chalmers RA, Roe CR, Stacey TE, Hoppel CL 1984 Urinary excretion of $l$ carnitine and acylcarnitines by patients with disorders of organic acid metabolism: evidence for secondary insufficiency of $l$-carnitine. Pediatr Res 18:1325-1328

10. Stumpf DA, Parker WD, Angelini C 1985 Carnitine deficiency, organic acidemias, and Reye's syndrome. Neurology (NY) 35:1041-1045

11. Brass EP, Hopell CL 1980 Relationship between acid-soluble carnitine and coenzyme A pools in vivo. Biochem J 190:495-504

12. Nakamura T 1985 Trends in coenzyme $Q_{10}$ research. J Syn Org Chem 43:1025

13. Hogeboom GH, Schneider WC, Paallade GE 1948 Cytochemical studies of mammalian tissues. 1. Isolation of intact mitochondria and submicroscopic particulate material. J Biol Chem 172:619-635

14. Chance B, Williams GR 1955 Respiratory enzymes in oxidative phosphorylation. 1. Kinetics of oxygen utilization. J Biol Chem 217:383-399

15. Bücher T 1947 Über ein phosphatübertragendes Gärungsferment. Biochim Biophys Acta 1:292-304

16. Lowry OH, Rosebrough NJ, Farr AL, Randall RJ 1951 Protein measurement with the Folin-phenol reagent. J Biol Chem 193:265-275

17. Chance B, Hagihara B 1963 Direct spectroscopic measurements of interaction of components of the respiratory chain with ATP, ADP, phosphate and uncoupling agent. In: Slater EC (ed) Proceedings of the International Congress of Biochemistry, 5th Congress, Moscow. Pergamon Press, Oxford, pp 3-33

18. Allred JB, Guy DG 1969 Determination of coenzyme A and acetyl CoA in tissue extracts. Anal Biochem 29:293-299

19. Ingebresten OC, Bakken AM, Farstad M 1982 The content of coenzyme A acetyl-CoA and long-chain acyl-CoA in human blood platelets. Clin Chim Acta 126:307-313

20. Alvira MA, Forman DT 1974 Biochemical abnormalities in Reye's syndrome. Ann Clin Lab Sci 4:447-483

21. Trauner DA 1982 Pathologic changes in a rabbit model of Reye's syndrome. Pediatr Res 16:950-953

22. Koga Y, Yoshino M, Yamashita F 1984 Effects of short and medium chain length fatty acids on pyruvate oxidation by cultured human fibroblasts and rat liver mitochondria. J Inherited Metab Dis 7:141-142

23. Parker WD, Haas R, Stumpf DA, Eguren LA 1983 Effects of octanoate on rat brain and liver mitochondria. Neurology (Cleve) 33:1374-1377

24. Ogburn PL, Sharp H, Lloyd-Still JD, Johnson SB, Holman RT 1982 Abnormal polyunsaturated fatty acid pattern of serum lipids in Reye's syndrome. Proc Natl Acad Sci USA 79:905-911

25. Greene HL, Wilson FA, Glick AD, Dunn GD, Kilroy AW 1976 Hepatic ATP concentrations and glycolytic enzyme activities in Reye syndrome. J Pediatr 89:777-780

26. Kang ES, Capaci MT, Korones DN, Tekade N 1982 Liver coenzyme A ester content: comparison between Reye's syndrome and control subjects. Clin Sci 63:455-460

27. Hulsmann WC, Elliott WB, Slater EC 1959 The nature and mechanism of action of uncoupling agents present in mitochrome preparations. Bioch Biophys Acta 39:267-276

28. Bjorntrop P, Ellis HA, Bradford RH 1963 Albumin antagonism of fatty acid effects on oxidation and phosphorylation reactions in rat liver mitochondria. J Biol Chem 239:339-344

29. Pressman BC, Lardy HA 1956 Effect of surface active agents on the latent ATPase of mitochondria. Bioch Biophys Acta 21:458-466

30. Bieber LL, Emaus R, Valkner K, Farrell S 1982 Possible functions of shortchain and medium-chain carnitine acyltransferases. Fed Proc 41:2858-2862

31. Mitchell ME 1978 Carnitine metabolism in human subjects 1 . Normal metabolism. Am J Clin Nutr 31:293-306

32. Utter MF, Keech DB 1963 Pyruvate carboxylase 1. Nature of the reaction. J Biol Chem 238:2603-2608

33. Shigesada K, Tatibana M $1978 \mathrm{~N}$-Acetylglutamate synthetase from rat liver mitochondria: partial purification and catalytic properties. Eur J Biochem $84: 285-291$ 